\title{
My Kingdom for a Horse: Resolving Conflicts of Interest in Asset Management*
}

\author{
Glenn Boyle ${ }^{\dagger}$ \\ New Zealand Institute for the Study of Competition and Regulation, \\ Victoria University of Wellington, Wellington, New Zealand \\ Graeme Guthrie \\ School of Economics and Finance, \\ Victoria University of Wellington, Wellington, New Zealand \\ Luke Gorton \\ Investment Banking Group, \\ Macquarie Bank Ltd
}

June 24, 2007

\footnotetext{
* Many people have been helpful to us in the course of this project. At Harness Racing New Zealand, Victor Rolton helped navigate us through the vast amount of information available on the HRNZ website and provided missing data, while Edward Rennell and Maria Morrison were invaluable sources of information about the New Zealand harness racing industry. Chris Bilson, Bruce Grundy, Martin Richardson, Phil O'Connor, Tom Smith and Roger Stover provided helpful comments on earlier drafts of the paper, as did workshop participants at ANU, Melbourne, Otago, Victoria, and the 2006 Asian Finance Association annual conference. Alysia Barnes, Rohan Boyle, Elizabeth Murray, Zheng Hong Zhu and Hanqing Wang all contributed essential research assistance, some of which was funded by Victoria University of Wellington Research Grant 23054. However, none of these is in any way responsible for remaining errors and ambiguities. None of the views expressed in this paper can be attributed to Macquarie Bank Limited or Harness Racing New Zealand.

${ }^{\dagger}$ Corresponding author: NZ Institute for the Study of Competition and Regulation, Victoria University of Wellington, Wellington, New Zealand. Email: glenn.boyle@vuw.ac.nz Phone: 64-4-463-7487 Fax 64-4-463-5566
} 


\title{
My Kingdom for a Horse: Resolving Conflicts of Interest in Asset Management
}

\begin{abstract}
Racehorse trainers operate asset management businesses in which the assets owned by outside clients compete with those owned by managers for the latter's time, care and attention. Although this potentially leads to serious conflicts of interest, we find no evidence of an agency problem: in a sample of 8000 racehorses and their associated stables, client-owned horses perform no worse than trainer-owned horses on average. However, this outcome is not uniform across stables: the average performance advantage of client-owned horses over their trainer-owned counterparts is positive in big stables where client-owners provide much of the trainer's income, but is negative in small stables with relatively few outside clients. Agents with more to lose apparently behave better.
\end{abstract}

JEL classification: J32, M52, D82, L14, L83

Keywords: agency; conflicts of interest; horse racing; asset management 


\section{My Kingdom for a Horse: Resolving Conflicts of Interest in Asset Management}

\section{Introduction}

In the standard agency setting, conflicting financial considerations can lead to shirking and/or a transfer of resources from principal to agent. For example, Levitt and Syverson (2005) and Rutherford et al. (2005) compare house sales in which the real estate agent acts on behalf of a client with sales where the agent is the seller, and find that agent-owned houses sell for approximately $4 \%$ more after controlling for differences in house characteristics. Similarly, Michaely and Womack (1999) compare the stock recommendations of underwriter-affiliated analysts with those of independent analysts and report that the latter are more credible along several dimensions.

However, not all conflicts of interest lead to problems. Gompers and Lerner (1999) find that initial public offerings apparently internalise the conflict of interest between investors and the investment banks that underwrite the securities offerings of firms they own: the latter are initially priced lower but subsequently perform just as well as securities underwritten by independent banks. Such findings are important because potential or perceived conflicts of interest often result in calls for government regulation. To the extent that markets are able to self-correct, such intervention is at best unnecessary.

Houses and stocks are traditional, and relatively conservative, asset classes. In this paper, we examine a potential agency problem that arises in a non-traditional, and highly speculative, asset class: the conflict of interest between owners and trainers in the horse racing industry. In return for preparing a horse for racing, trainers receive a fixed fee from owners plus a proportion ( $10 \%$ in the setting we examine) of horse winnings. However, they also train horses on their own account, from which they receive $100 \%$ of winnings. Such an arrangement creates an obvious incentive for trainers to divert effort and overall training quality from horses owned by clients to horses owned by themselves, particularly given the difficulties faced by clients in monitoring and assessing trainer inputs. By comparing the success of horses that are trainer owned with those that are not, we can explicitly identify the difference in performance between, on the one hand, an asset manager acting on behalf of a client and, on the other hand, the same manager acting on his own behalf.

To undertake this comparison, we hand-collect information on the ownership and performance of approximately 8000 standardbred racehorses and their associated trainers and stables. Despite the incentive for trainers to exploit clients, we find no evidence of an agency problem: on average, client-owned horses perform approximately $12 \%$ better than trainer-owned horses, after controlling for relevant horse and trainer characteristics. Every $\$ 10,000$ earned by the typical 
horse when trainer owned becomes approximately $\$ 11,220$ when client owned.

What might account for this surprising result? A possible, and appealing, explanation is that the market for horse training services is sufficiently transparent to provide trainers with the right incentives, notwithstanding the difficulties faced by clients in monitoring trainer effort. Each stable relies, to varying degrees, on the continued patronage of outside clients, and so competes with other stables for the custom of these clients. ${ }^{1}$ To the extent that trainers divert effort towards horses they own themselves, they risk losing income as clients become dissatisfied with the performance of their horses and consequently transfer them to another stable. Such future-income concerns may persuade trainers to act in the best interests of their clients.

The main results of this paper provide evidence consistent with this view. In stables that have little to lose from upsetting clients - small stables and stables with relatively few outside clients - trainer-owned horses do better on average than client-owned horses, just as the standard agency model would suggest. But the reverse is true in stables where outside clients provide the bulk of a trainer's income. Although the compensation structure for horse trainers encourages the exploitation of clients, trainers who have a lot to lose from upsetting clients apparently choose to put client interests first.

While gambling data from the horse racing industry have been widely used to test hypotheses about market efficiency and investor preferences (e.g., Hausch et al, 1994; Hurley and McDonough, 1995. Sauer, 1998), the potential value of internal industry data for other research areas has largely gone unrecognized..$^{2}$ These data possess some unique features relevant to analysis of agency problems. First, because horse races take place frequently, there is a wealth of publicly available information. Second, performance is easily measured by horse success. Third, trainer ownership of horses is relatively common, so the potential agency problem occurs on a regular basis.

In the next section, we provide some background information on the specific horse racing industry we examine. Section 3 then describes our data and undertakes some preliminary analysis. Sections 4 and 5 present our main results, while Section 6 offers some concluding remarks.

\section{The New Zealand harness racing industry}

Despite there being no shortage of data on horse race outcomes and their associated features, much of this is not available in a user-friendly form. Fortunately, Harness Racing New Zealand (HRNZ), the governing body of New Zealand (NZ) harness racing, has since 2001 provided information on its website (www.hrnz.co.nz) about the owners, trainers and performance of

\footnotetext{
${ }^{1}$ We use the term 'stable' to denote the group of horses prepared by a trainer, i.e., the trainer's 'firm'.

${ }^{2}$ The sole exception seems to be Fernie and Metcalf (1999), who find that UK jockeys on incentive contracts generally perform better than those on fixed retainers. However, their sample size is small and they conduct no formal statistical tests.
} 
every standardbred horse that has raced in NZ since the 1985-86 season, as well as full results for every race that occurred during that period. ${ }^{3}$ This data set is, as far as we know, unique in terms of the rich and detailed information it provides about arrangements in the horse racing industry. ${ }^{4}$ In the next section, we describe this data resource in more detail. This section lays out some basic institutional information about the industry.

The statute that controls NZ racing — The Racing Act — gives responsibility for administration of the racing industry to the NZ Racing Board, which in turn devolves day-to-day control to the governing bodies of the three codes - harness racing (HRNZ), thoroughbred racing (NZ Throughbred Racing), and greyhound racing (NZ Greyhound Racing). In the case of HRNZ, one of its most important functions is the licensing of trainers, which requires intending trainers to pass practical and oral tests dealing with the care and preparation of standardbred horses. Having received a license, trainers are subject to the Terms and Conditions of Training mandated by the NZ Harness Racing Trainers and Drivers Association, which specify the rights and obligations of trainers and owners. In particular, this mandates that trainers must receive a fixed daily fee from owners and $10 \%$ of all horse winnings. It also spells out what the fixed fee does and does not cover, and what other costs owners are likely to incur. Thus, the contracts agreed between owners and trainers are homogeneous. ${ }^{5}$

Owners and trainers come together in a variety of ways. In some cases, an owner brings a pre-purchased horse to a trainer; in other cases, the owner arranges assistance from a trainer in buying a horse prior to it entering training; while in still other cases a trainer may seek out owners for purchase of a horse that he believes has potential. In all of these situations, the trainer may or may not become an owner. Finally, some horses are obtained by trainers on their own behalf, for racing in their own or their family's name.

Having been placed in a stable, whether in the ownership of the trainer, an outside client, or both, a horse is then prepared for racing. Although two- and three-year old horses race mainly against their own age group, most horses are subject to the NZ handicapping system, which attempts to bring together horses of similar ability. For our purposes, this has two principal implications. First, with only a few exceptions, horses move up a class every time they win a race. Thus, success is difficult to maintain for most horses because they eventually "reach their mark". Second, horses must usually qualify — via strong prior performance — for high-stakes races.

Finally, although apparently an industry in decline (see Grant, 2000; Tolich, 2002), the economic impact of NZ horse racing is non-trivial. IER (2004) estimate that this industry

\footnotetext{
${ }^{3}$ The NZ racing season runs from 1 August to 31 July.

${ }^{4}$ In principle, similar information could be obtained from the United States Trotting Association website (http://pathway.ustrotting.com/ecommerce/reportdescript.cfm), but doing so is considerably more difficult than on the HRNZ site and, moreover, is costly.

${ }^{5}$ The uniformity of trainer commission rates is itself an interesting phenomenon, although not one we investigate in this paper. For a similar clustering of commission rates in other industries, see Chen and Ritter (2000) and Hsieh and Moretti (2003).
} 
produced output worth more than $\$ 1.4$ billion (all figures are in NZ dollars) during 2002-03, approximately $1.2 \%$ of NZ gross domestic product and supporting over 18,000 employees. Henley Centre (2004) reports comparable GDP shares for racing industries in other countries: Australia $(0.8 \%)$, Ireland $(0.2 \%)$, United Kingdom $(0.3 \%)$, and United States $(0.2 \%)$.

The rest of this paper examines whether variation in a trainer's ownership role has any systematic impact on performance, and if so, in what circumstances. Given the $10 \%$ rule noted above, trainers have an obvious incentive to devote more time, effort and general training quality to horses they at least partly own, suggesting that trainer-owned horses should perform better on average.

\section{Data}

Our data set contains details on every horse that competed in NZ harness races during the 1997-98 and 2002-03 seasons. Starting with the first race at the first meeting of the 1997-98 season, we record the age, sex, trainer, winnings, and ownership details of the winning horse. Using the HRNZ website, we then track this horse through the rest of the season, recording performance details for each race plus any changes in trainer or ownership. ${ }^{6}$ We repeat this procedure for every other horse in the same race, then move to the second and subsequent races at the same meeting, and so on through all meetings and races held during the 1997-98 season. Finally, we repeat the whole exercise for the 2002-03 season. Because of the relatively short racing life of horses, this gives us two independent samples.

In 1997-98, there were 237 meetings at which 2345 races were contested by 3448 horses who raced a total of 27451 times; for 2002-03, these figures were 232 meetings, 2350 races, 3263 horses and 27126 horse-races. Some horses changed trainers during the season, or switched between client- and trainer-ownership. Each such change was treated as a different horse, leading to a final dataset of 4087 horses in 1997-98 and 3861 in 2002-03. The respective trainer numbers are 984 and 852 .

Table 1 provides some summary statistics for the horses in our sample. In both seasons, the average horse is between four and five years old, races six or seven times, earns $\$ 4000$ $\$ 5000$ (out of a possible $\$ 30,000-\$ 36,000$ ) for its two to three co-owners, and has an almost $60 \%$ chance of being male. However, some of these characteristics vary considerably across horses: the standard deviations for the number of races and the number of owners are almost as large as their respective means, while the standard deviations for earnings are almost three times as large as the corresponding means.

Our primary interest is in the relationship between horse performance and whether or not it races in the interest of its trainer. Although we know the identity of each horse's owners,

\footnotetext{
${ }^{6}$ Because the precise dates of changes in ownership or stable were often difficult to identify from the website, we subsequently obtained this information directly from HRNZ. We are grateful to Victor Rolton for assisting us with this.
} 
Table 1: Horse Descriptive Statistics

This table provides summary information about the horses in our dataset. Trainer-owned horses are those where the trainer has at least a partial ownership share. Race starts is the number of races in which the horse competes during the season. Maximum season earnings is equal to total possible stake winnings if all races are won. Ownership group size is the number of individuals who share ownership of the horse.

\begin{tabular}{|c|c|c|c|c|c|c|c|c|c|c|}
\hline \multirow[b]{2}{*}{ Characteristic } & \multicolumn{5}{|c|}{$\begin{array}{c}1997-1998 \\
(n=4087, \text { of which } 59 \% \text { are male } \\
\text { and } 39 \% \text { are trainer-owned) }\end{array}$} & \multicolumn{5}{|c|}{$\begin{array}{c}2002-2003 \\
(n=3861, \text { of which } 58 \% \text { are male } \\
\text { and } 36 \% \text { are trainer-owned })\end{array}$} \\
\hline & Mean & Std dev & Median & Min & $\operatorname{Max}$ & Mean & Std dev & Median & Min & Max \\
\hline Age (years) & 4.6 & 1.6 & 4 & 2 & 11 & 4.4 & 1.5 & 4 & 2 & 13 \\
\hline Race starts & 6.7 & 5.8 & 5 & 1 & 43 & 7.0 & 5.8 & 5 & 1 & 45 \\
\hline Season earnings $(\$ 1000)$ & 4.2 & 12.6 & 0.7 & 0 & 302.5 & 5.0 & 14.3 & 1.3 & 0 & 396.7 \\
\hline Max. season earnings $(\$ 1000)$ & 30.1 & 46.3 & 15.8 & 0.6 & 671.9 & 36.2 & 58.4 & 18.8 & 1.1 & 896.0 \\
\hline Ownership group size & 2.6 & 2.2 & 2 & 1 & 10 & 2.7 & 2.3 & 2 & 1 & 10 \\
\hline
\end{tabular}

their specific ownership shares are not publicly available. Thus, we distinguish only between horses in which the trainer has some ownership share (henceforth trainer-owned) and those that are completely client-owned. This simple categorization is not solely a data-induced necessity. By defining as trainer-owned any horse in which the trainer simply has a non-zero ownership interest, we guard against the possibility, to be discussed in more detail later, that trainer horseownership is constrained by affordability issues. In our sample, $39 \%$ of horses are trainer-owned during the 1997-98 season and 36\% during the 2002-03 season.

An obvious measure of performance is total season earnings, but this is of doubtful validity for our purposes. Because total earnings are largely determined by horse eligibility to compete in high stakes races, which in turn primarily reflects horse performance in previous seasons, a horse could perform poorly in the current season but nevertheless earn more than a consistentlyperforming horse simply because its efforts in previous seasons qualified it for higher-stakes races (which may have occurred in a different stable under different ownership). To get round this problem, we instead use two performance measures that attempt to capture the extent to which a horse races to its potential. The first, commonly used in the industry itself, measures the regularity with which the horse finishes in a position that pays a significant stake to owners:

$$
\text { consistency ratio }=\frac{9 \times \text { number of firsts }+5 \times \text { number of seconds }+3 \times \text { number of thirds }}{9 \times \text { number of races during season }}
$$

The second measures the extent to which a horse achieves its maximum-possible earnings:

$$
\text { earnings ratio }=\frac{\text { stake earnings during the season }}{\text { sum of winning stakes from all races entered during the season }}
$$

The two performance measures are quite highly correlated, but the latter gives more weight to high-stakes races. This feature recognises that trainers may use their experience and knowledge 
Table 2: Horse Ownership and Performance: Comparison of Means

The first two columns for each season report the mean performance of horses in which the trainer has an ownership stake and those in which he does not. The third column calculates the difference and associated standard error (in parentheses). Consistency ratio is a weighted average estimate of a horse's propensity to be among the first three placegetters. Earnings ratio is total earnings divided by maximum-possible earnings. ${ }^{* * *}$ denotes significance at the $1 \%$ level.

\begin{tabular}{lcccccc}
\hline \hline & & $\begin{array}{c}1997-1998 \\
(n=4087)\end{array}$ & & & $\begin{array}{c}2002-2003 \\
(n=3861)\end{array}$ & \\
Variable & Trainer-owned & Client-owned & Difference & Trainer-owned & Client-owned & Difference \\
\hline $\begin{array}{c}\text { Consistency } \\
\text { ratio }\end{array}$ & 0.117 & 0.146 & $\begin{array}{c}-0.029^{* * *} \\
(0.006)\end{array}$ & 0.120 & 0.162 & $\begin{array}{c}-0.042^{* * *} \\
(0.006)\end{array}$ \\
$\begin{array}{c}\text { Earnings } \\
\text { ratio }\end{array}$ & 0.089 & 0.108 & $\begin{array}{c}-0.019^{* * *} \\
(0.005)\end{array}$ & 0.095 & 0.126 & $\begin{array}{c}-0.032^{* * *} \\
(0.005)\end{array}$ \\
\hline \hline
\end{tabular}

to prepare a horse for the big occasion by racing its way to fitness in lesser races. If this strategy is successful, the horse's consistency ratio would be low, but its earnings ratio would be high. ${ }^{7}$

Table 2 reports the mean values of these two performance measures for both client-owned and trainer-owned horses. Surprisingly, client-owned horses perform significantly better than trainer-owned horses on average: the former are 25\%-35\% more consistent and 21\%-33\% better at realising their potential winnings. Despite trainers having a strong incentive to devote more time and effort to horses they own themselves, these results are not suggestive of an agency problem: horses owned by outside clients do not just perform as well as trainer-owned horses, they actually perform much better.

Of course, other variables that potentially affect horse performance, such as horse and trainer quality, may also be correlated with horse ownership in our sample. In particular, outside clients may be better financially positioned to own the best horses. In the next section, we attempt to deal with such issues by estimating multiple regression models that include various control variables.

\section{Is there an agency problem?}

We first estimate regression models of the general form

$$
\text { horse performance }=\alpha_{0}+\alpha_{1}(\text { client owner })+\sum_{i} \beta_{i}\left(\operatorname{control}_{i}\right)+\varepsilon,
$$

\footnotetext{
${ }^{7}$ These performance measures could be misleading if trainers were able to play 'games' in their own interests by entering client-owned horses in low-stakes races where the competition is weak while simultaneously entering their own in high-stakes events against strong competition. All else equal, client-owned horses would then perform better according to our measures, and we might wrongly conclude that there is no agency problem. However, the ability of trainers to act in this way is severely constrained by the handicapping system discussed in Section 2: successful horses cannot race perpetually in low-grade events, and entry in high-stakes races requires prior qualification.
} 
where 'client owner' equals 1 if the trainer is not one of the horse's owners and 0 otherwise, and each 'control' $i$ ' is a variable that potentially influences horse performance over the course of a season..$^{8}$

Horse performance over a season is primarily determined by three factors: horse quality, trainer quality, and importance of the horse to the trainer (i.e., trainer motivation). For horse quality, we employ three measures: age, sex, and intrinsic ability. Horse speed and stamina typically decline beyond four-five years of age, so we expect our performance measures to be inversely related to age. ${ }^{9}$ Also, male horses are generally more robust than females, which is likely to result in better performance. We therefore employ an indicator variable that is equal to 1 if the horse is male and 0 otherwise.

Even allowing for differences in age and sex, some horses simply have greater ability than others and thus will perform better on average. Unfortunately, intrinsic horse ability is not directly observable. An obvious proxy is some measure of historical performance, such as the previous season's earnings. However, this would be equal to zero for many horses in our sample, due to their not having raced in a prior season, and so would fail to distinguish between many horses of different ability. ${ }^{10}$ Instead, we exploit the fact that those with the best knowledge about a horse's ability are those closest to it - its trainer and owners. If they believe the horse to be of high ability, they will seek to enter it in high-quality races offering high stakes. If, on the other hand, they consider it to be of more modest ability, they are more likely to restrict it to low-stakes races where it has a greater chance of paying its way. To capture this 'insider knowledge' about horse ability, we calculate the horse's maximum-possible season earnings (i.e., the amount of money it would have earned if it had won all its races) as a proxy for beginningof-season expectations by insiders about future horse performance. The greater this amount, the higher the confidence of the horse's principal connections about its ability. ${ }^{11}$

Horses of identical ability may perform differently because of differences in the quality of their training; all else equal, better training will result in better performance. We control for this in two ways. First, we use average annual stake earnings of the trainer's stable during the previous five seasons as a proxy for trainer quality. Second, trainer effort might be motivated by financial considerations unrelated to ownership; for example, a horse racing for high stakes may be worth spending more time and effort on than one confined to minor races, even if the trainer owns the latter and not the former, e.g., $10 \%$ of $\$ 100,000$ is more than $100 \%$ of $\$ 5000$. This

\footnotetext{
${ }^{8}$ Because we focus on horse performance over a season, we do not consider race-specific determinants of performance such as barrier draw, track conditions, and race distance. However, we implicitly consider the importance of these variables in unreported analysis that restricts our sample to horses that race at least five times during the season. This has little effect on the results.

${ }^{9}$ Although young horses (two and three year-olds) lack experience, which could be expected to worsen performance, they primarily race only against each other.

${ }^{10}$ Other possible indicators of ability, such as breeding index scores or sales ring prices, either do not exist or are unavailable for the horses in our data.

${ }^{11}$ Scaling this variable by the number of races the horse has during the season yields very similar results.
} 
suggests that the more important a horse is to the overall stable, the greater the effort likely to be put into it, and hence the better its performance. To capture this effect, we calculate the ratio of horse maximum possible earnings to the average of maximum possible earnings across all horses in the stable and use this as a proxy for the importance of the horse to its stable.

In these regression models, the client-owner coefficient estimates the average performance superiority of client-owned horses. This implicitly assumes that the allocation of owners to horses is exogenous, but two phenomena (that work in opposite directions) make this unlikely. First, trainers generally have more information and knowledge about horse quality and ability than clients, and so can be expected to use this advantage to purchase ownership only in the horses most likely to succeed. Second, wealthy outside owners who face weaker financial constraints than trainers may disproportionately purchase the highest-quality horses that subsequently perform best. The first of these implies that trainer-owned horses should perform better regardless of any agency-induced differential effort; the second implies the opposite. To the extent that one or other of these dominates, any performance difference between client- and trainer-owned horses may simply reflect the endogenous determination of ownership, rather than trainers' responses to the conflict of interest inherent in their remuneration structure. ${ }^{12}$

To some degree at least, these endogoneity problems should be mitigated by the inclusion of a proxy for horse ability in our regressions. Moreover, with regard specifically to the 'trainer capital constraints' effect, two other factors are also likely to help. First, we define a trainerowned horse as one in which the trainer has some ownership share: although trainers may indeed face greater financial constraints than clients in owning $100 \%$ of a horse, this need not preclude them from owning some portion. Second, client owners possessing a valuable horse are unlikely to entrust its care to a poor trainer, so the trainer quality variable provides an indirect control for any biases created by greater client wealth.

Another possible problem with our regression model is that in the specifications where the dependent variable is the earnings ratio, maximum-possible earnings appears on both sides of the equation, creating the potential for a spurious negative relationship between our performance and horse ability variables. However, this does not seem to be a major issue here. First, as we shall see, the estimated relationship between performance and ability is strongly positive, so the behavioral link between these two variables appears to dominate the mechanical. Second, the problem does not arise when the consistency ratio is the dependent variable and, again as we shall see, the two performance measures yield very similar results.

Table 3 presents regression results for both seasons, both performance measures, and two model specifications. In columns (1) and (3) of each panel, we control for horse age and sex, which lowers the estimated impact of outside ownership compared with the simple mean differences reported in Table 2. For example, the average improvement in the consistency ratio for horses with no trainer ownership in 1997-98 is now 0.023, compared with 0.029 in Table 2. Nevertheless,

\footnotetext{
${ }^{12}$ In the case of trainer informational advantages, there may, of course, still be an agency problem, but one with adverse selection, rather than moral hazard, origins.
} 
these differences are still significant at the $1 \%$ level or better. In columns (2) and (4) of each panel, we add the additional control variables. This has a more substantial effect on the impact of outside ownership, but all the ownership coefficients remain statistically and economically significant.

Some simple calculations illustrate the quantitative impact of client ownership. For example, evaluating column (2) of panel B at sample average values, the typical horse in the 199798 sample has a predicted earnings ratio of 0.094 if trainer owned and 0.104 if client owned. Using column (4) of the same panel, the corresponding figures for 2002-03 are 0.109 and 0.124 respectively. Over both seasons, the predicted earnings ratio is about $12 \%$ greater if client owned. Put another way, for every $\$ 10,000$ earned by the typical horse when trainer owned, it wins approximately $\$ 11,220$ when client owned.

Although the control variables are not our primary focus, it is comforting to know that their coefficients seem sensible. In all specifications, horses that are male, score highly on our proxy for intrinsic ability, and are prepared by high-quality trainers do better, while older horses do worse. Client ownership has roughly the same average impact on horse performance as a year less of age, an extra $\$ 100,000$ per season of historical trainer success, or an extra $\$ 30,000$ in maximum-possible earnings. The marginal impact of client ownership is approximately half that of being male.

Overall, the results in Table 3 reject the simple agency model. Even after controlling for characteristics such as age, sex, and horse and trainer quality, client-owned horses on average out-perform trainer-owned horses by an economically significant amount, despite trainers having the incentive and opportunity to favor their own horses.

\section{$5 \quad$ Stable-level analysis}

The analysis in Section 4 documents a positive relationship between client ownership and horse performance. It is tempting to conclude that, notwithstanding the difficulties faced by owners in observing and monitoring trainer effort, the market for horse training services is sufficiently transparent to provide trainers with the right incentives. But such a conclusion would be premature. Perhaps the relationship is spurious due to the ownership variable being correlated with some unknown determinant of horse performance; for example, if client owners tend to place their horses with trainers of proven ability, then the superior performance of client-owned horses may primarily reflect their receiving training services that are 'better' along some dimensions not picked up by our trainer quality variable. Or perhaps client owners monitor their horse's preparation more closely if the trainer is not also an owner.

If the results of Section 4 do indeed indicate desirable incentives at work, then the performance advantage of client-owned horses should be strongest in stables that have the most to lose from exploiting their clients. Trainers who allocate greater effort to horses they own themselves risk alienating clients who, dissatisfied with the performance of their horses, then transfer them 
Table 3: Horse Ownership and Performance: Multiple Regression Analysis

Regressions of horse performance on ownership and horse and trainer characteristics. The dependent variables in panels A and B are the consistency ratio and earnings ratio respectively. Both the dependent variables are defined in Table 2. Client owner equals 1 if the horse is not owned by its trainer and 0 otherwise. Male equals 1 if the horse is male and 0 otherwise. Trainer quality is the average stakes won by the horse's trainer over the previous five seasons (in $\$ 100,000$ ). Horse quality is the horse's total possible stake winnings if all races during the season are won (in $\$ 100,000$ ). Horse contribution to stable is the ratio of horse maximum possible stake winnings to the average maximum possible stake winnings over all horses in the same stable. Terms in parentheses are White (1980) heteroskedasticity-robust standard errors. ${ }^{* * *}$ denotes significance at the $1 \%$ level, ${ }^{* *}$ at the $5 \%$ level, and ${ }^{*}$ at the $10 \%$ level.

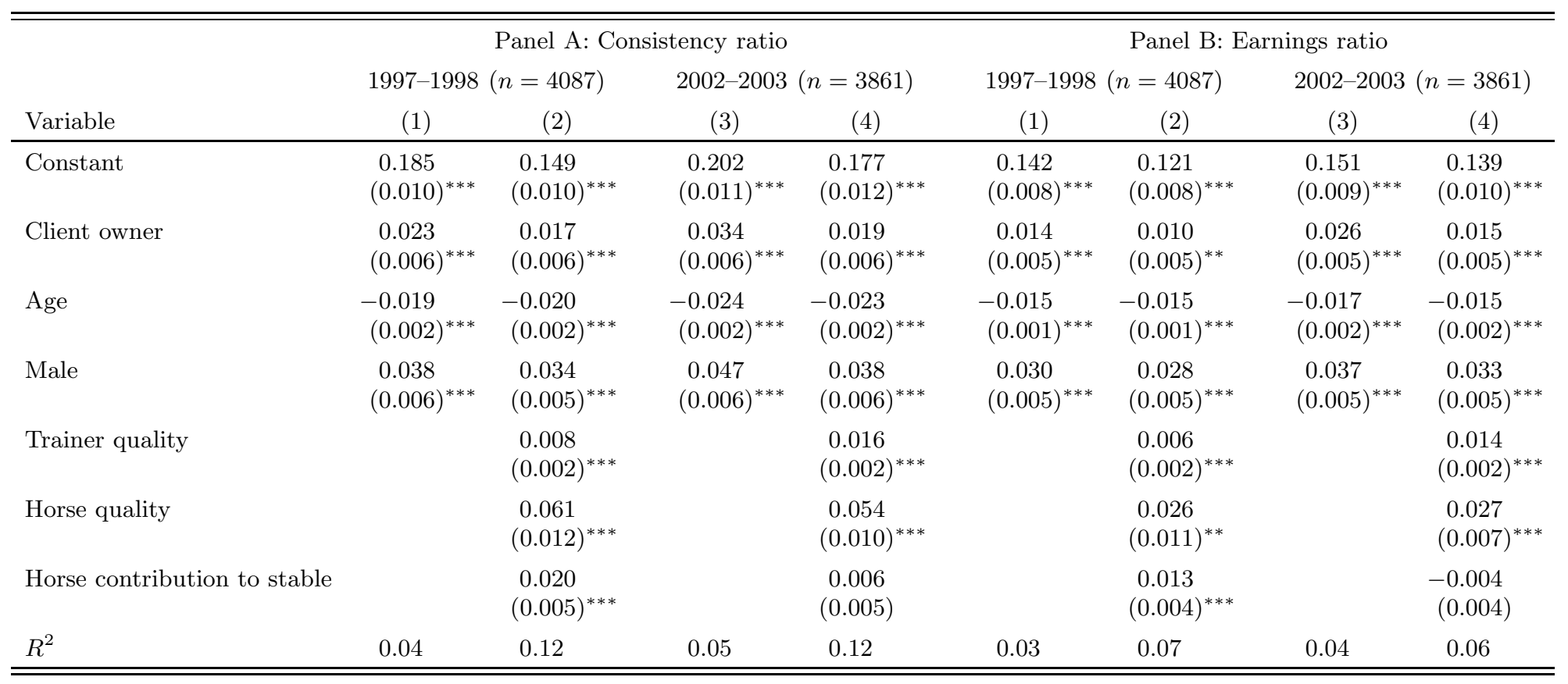


to other stables, thereby depriving the trainer of income. In practice, however, the strength of this incentive varies across stables. Trainers earn income in a variety of ways: not only from providing training services, but also from buying and selling horses, from racing-related activities (e.g., farrier work, education of young horses), and from activities unrelated to racing (e.g., farming). Clearly, a trainer for whom training activities are little more than a part-time hobby has little reliance, if any, on his ability to attract and retain outside clients, since the failure to do so will have few financial consequences. By contrast, trainers who are dependent on training activities for the bulk of their income will be more concerned about maintaining a healthy supply of clients. ${ }^{13}$

We use two measures to capture the strength of a stable's desire to satisfy outside clients. First, stable size, as measured by the number of horses raced by the stable during the season. Trainers with large stables are presumably most dependent for their income on the provision of training services, and hence are highly motivated to keep clients happy. Moreover, large stables are able to generate economies of scale, and so will wish to protect the ensuing rent. By contrast, a trainer who runs a small stable and derives the majority of his income from non-training sources has less to lose from putting his own interests first. Second, the ownership ratio, as measured by the number of client-owned horses raced by the stable during the season divided by the number of trainer-owned horses. As well as being a more direct measure of the importance of client-owned horses to a stable, this variable allows us to distinguish between small stables that are small due to the bulk of the trainer's livelihood coming from elsewhere (and hence having weak incentives to treat clients correctly), and small stables that are small due to the trainer being relatively new to a training career (and therefore wishing to establish a good reputation). Because the latter are likely to be more financially constrained, they will tend to own few horses themselves and hence have a high proportion of client-owned horses among the small number of horses they prepare.

To determine whether the difference in performance between client- and trainer-owned horses varies with the importance of the former to a stable's total income, we construct trainer-owned and client-owned 'horse portfolios' for each stable, calculate the performance of each portfolio, and investigate whether the difference between them is related to our two client-dependence variables. Forming stable-based portfolios in this way effectively neutralizes trainer quality effects, since superior training ability should, other motivations the same, improve the performance of both client- and trainer-owned horses equally, leaving the difference unchanged.

For this exercise, we combine our two seasons of data and exclude those stables that do not contain at least one client-owned horse and one trainer-owned horse; this leaves a total of 572 stables. For each stable, we compute and record the characteristics (performance, age, sex,

\footnotetext{
${ }^{13}$ This idea has antecedents in the theoretical models of Williams (1998), Telser (1980), Klein and Leffer (1981), and Fama (1980). Although the specific mechanisms underlying these models are somewhat different, they share a common implicit theme: that the need to compete for clients can lessen the problems arising from conflicts of interest.
} 
Table 4: Stable Descriptive Statistics

This table provides summary information about the stables in our two-season sample. A total of 572 trainers prepare both client-owned and trainer-owned horses over the two seasons. Consistency (Earnings) Ratio Premium equals the consistency (earnings) ratio for the stable's portfolio of clientowned horses minus the consistency (earnings) ratio for the stable's portfolio of trainer-owned horses. Age difference is the average age of the stable's client-owned horses minus the average age of its trainer-owned horses. Male difference is the proportion of males among the stable's client-owned horses minus the proportion of males among its trainer-owned horses. Quality difference is the average maximum-possible stake earnings of the stable's client-owned horses minus the average maximum-possible stake earnings of its trainer-owned horses. In the first five rows, ${ }^{* * *}$ denotes that the mean value differs from zero at at the $1 \%$ significance level, ${ }^{* *}$ at the $5 \%$ level, and ${ }^{*}$ at the $10 \%$ level. In the last two rows, Stable size is the number of horses raced by the stable during the two seasons covered by our sample, while Ownership ratio is the number of horses in the stable's client-owned portfolio divided by the number in its trainer-owned portfolio.

\begin{tabular}{lccccc}
\hline \hline Variable & Mean & Std dev & Median & Min & Max \\
\hline Consistency ratio premium & $-0.012^{* *}$ & 0.14 & 0.00 & -0.80 & 0.56 \\
Earnings ratio premium & $-0.007^{*}$ & 0.11 & 0.00 & -0.80 & 0.42 \\
Age difference & 0.032 & 1.43 & 0.00 & -6.00 & 6.00 \\
Male difference & $-0.035^{*}$ & 0.47 & 0.00 & -1.00 & 1.00 \\
Quality difference $(\$ 100,000)$ & $-0.058^{* * *}$ & 0.34 & -0.026 & -3.13 & 1.19 \\
Stable size & 10.80 & 12.8 & 6.00 & 2 & 115 \\
Ownership ratio & 3.205 & 6.016 & 1.00 & 0.091 & 68 \\
\hline \hline
\end{tabular}

maximum earnings and ownership) of the group of horses owned by the trainer and, separately, those owned by clients. We compute the performance advantage of the latter group as:

$$
\begin{aligned}
\text { performance premium }= & \text { performance of stable's client-owned horses } \\
& - \text { performance of stable's trainer-owned horses }
\end{aligned}
$$

for both the consistency and earnings ratio measures of performance. We regress these performance premia on one of our two measures of stable client-dependence, and on the following variables controlling for differential horse ability: (i) the average age of the stable's client-owned horses minus the average age of its trainer-owned horses, (ii) the proportion of males among the stable's client-owned horses minus the proportion of males among its trainer-owned horses, and (iii) the average maximum-possible stake earnings of the stable's client-owned horses minus the average maximum-possible stake earnings of its trainer-owned horses. In all specifications, we use the natural log of our client-dependence variables, since any effect of these on trainer incentives is likely to diminish beyond a certain point.

Table 4 contains summary statistics for these variables. In the average stable, there is little age or sex difference between client- and trainer-owned horses, but the latter race for greater stakes (consistent with trainers having better information about horse potential). And, 
Table 5: Stable Performance, Ownership, and the Importance of Outside Clients: Comparison of Means

This table reports the mean difference in performance between a stable's portfolio of client-owned horses and its portfolio of trainer-owned horses, conditioned on whether the stable is above or below the sample median for our two measures of outside-client dependence. All variables are defined in Table $4 .{ }^{* * *}$ denotes significance at at the $1 \%$ level, ${ }^{* *}$ at the $5 \%$ level, and ${ }^{*}$ at the $10 \%$ level.

\begin{tabular}{lcc}
\hline \hline & Consistency ratio premium & Earnings ratio premium \\
\hline Stable size $>$ sample median & -0.001 & 0.001 \\
Stable size $\leq$ sample median & $-0.222^{* * *}$ & $-0.015^{* *}$ \\
Difference & $-0.021^{*}$ & $-0.017^{*}$ \\
Ownership ratio $>$ sample median & 0.006 & 0.007 \\
Ownership ratio $\leq$ sample median & $-0.029^{* * *}$ & $-0.020^{* * *}$ \\
Difference & $-0.035^{* * *}$ & $-0.027^{* * *}$ \\
\hline \hline
\end{tabular}

in contrast to the previous horse-focused analysis, mean performance at the stable level is better among trainer-owned horses, although the earnings ratio difference is statistically significant only at the $10 \%$ level. Grouping the horses into stable portfolios effectively reduces the statistical weight allocated to horses that are trained in large stables; the weaker performance advantage of client-owned horses in this stable-based analysis therefore provides tacit support for the view that large stables face sharper incentives in dealing with clients.

Table 5 explores this idea in more detail by splitting our sample of 572 trainers into two groups - those above and below the sample medians for, successively, stable size and ownership ratio - and then calculating the mean performance premium for each group. In general, stables that are relatively large, or that contain a relatively high proportion of client-owned horses, tend to see their client-owned horses perform slightly better than their trainer-owned counterparts, although the difference is statistically insignificant. By contrast, relatively small stables, and stables with a relatively low proportion of client-owned horses, are associated with trainer-owned horses having a significant performance edge of between 1.5 and 3 percentage points.

Table 6 confirms that these results are unaffected by including the control variables in the regressions described above. The more a stable has to lose from upsetting clients, the bigger the performance advantage of the client-owned group of horses. For example, holding all else equal, doubling either stable size or the ownership ratio raises the average performance premia by $0.012-0.015$ points, amounts greater (in absolute value) than their respective sample means. Setting other variables equal to their sample means, moving from the 10th to the 90th percentile of the stable size variable raises the predicted consistency ratio difference between the clientand trainer-owned horses from -0.029 to 0.005 , and the predicted earnings ratio difference from -0.023 to 0.008 . Similarly, moving from the 10th to the 90th percentile of the ownership ratio variable raises the predicted consistency ratio premium from -0.034 to 0.013 , and the predicted 
Table 6: Stable Performance, Ownership, and the Importance of Outside Clients: Regression Analysis

This table estimates the impact that ex-ante measures of the importance of outside clients to a stable have on the performance-ownership relationship. In all regressions, the sample size is 572 , and the dependent variable is the difference between the performance measure for the stable's portfolio of client-owned horses and the same performance measure for its portfolio of trainer-owned horses. All variables are defined in Table 4. Terms in parentheses are White (1980) heteroskedasticity-robust standard errors. ${ }^{* * *},{ }^{* *}$ and ${ }^{*}$ denote significance at the $1 \%, 5 \%$ and $10 \%$ level respectively.

\begin{tabular}{lcccc}
\hline \hline & \multicolumn{4}{c}{ Dependent variable } \\
& Consistency ratio premium & Earnings ratio premium \\
\hline Constant & $-0.029^{*}$ & -0.007 & $-0.026^{* *}$ & -0.006 \\
& $(0.016)$ & $(0.006)$ & $(0.013)$ & $(0.200)$ \\
Age difference & $-0.022^{* * *}$ & $-0.022^{* * *}$ & $-0.013^{* * *}$ & $-0.014^{* * *}$ \\
& $(0.005)$ & $(0.005)$ & $(0.003)$ & $(0.003)$ \\
Male difference & $0.034^{* * *}$ & $0.035^{* * *}$ & $0.024^{* *}$ & $0.025^{* *}$ \\
& $(0.013)$ & $(0.013)$ & $(0.010)$ & $(0.010)$ \\
Quality difference & $0.138^{* * *}$ & $0.137^{* * *}$ & $0.076^{* * *}$ & $0.076^{* * *}$ \\
$(\$ 100,000)$ & $(0.028)$ & $(0.027)$ & $(0.019)$ & $(0.018)$ \\
$\log ($ Stable size $)$ & $0.014^{* *}$ & & $0.012^{* *}$ & \\
& $(0.007)$ & & $(0.005)$ & \\
$\log ($ Ownership ratio $)$ & & $0.015^{* * *}$ & & $0.013^{* * *}$ \\
& & $(0.005)$ & & $(0.003)$ \\
$R^{2}$ & 0.15 & 0.16 & 0.10 & 0.11 \\
\hline \hline
\end{tabular}

earnings ratio premium from -0.025 to 0.013 .

A stable's dependence on outside clients thus appears to be an important determinant of relative performance: client-owned horses perform significantly worse than trainer-owned horses in stables that receive little of their income from outside clients, but the reverse is true in stables where these clients are more prominent. Agents with a lot to lose apparently behave much better.

\section{Concluding remarks}

Although horse trainers have a direct financial incentive to devote more time, care and attention to horses that they own themselves, the average performance of these horses is inferior to that of horses they prepare for clients. This appears to reflect the fact that most horses are trained in large stables that have a lot to lose from upsetting clients: the performance premium of clientowned horses is positive in these stables, but is negative in stables where client satisfaction is less important. Overall, our results suggest that the market for horse training services is sufficiently transparent to motivate trainer effort in a way that is consistent with the interests of clients.

A possible objection to this conclusion concerns the role of trainer capital constraints in determining horse ownership. Perhaps client-owned horses are simply better than trainer-owned 
horses on average, due to the greater purchasing power of wealthy clients. If the latter then choose to place these horses in large stables — which seems plausible - then the positive impact of stable size on the performance of client-owned horses may have nothing to say about differential trainer effort. Against this, we offer three pieces of counter-evidence. First, we categorize trainer-owned horses as those in which the trainer has just some ownership share (which may be considerably less than 100\%), thereby minimizing the possible impact of financial constraints on trainer ownership. Second, our results are equally strong when the measure of client dependence is the ratio of client- to trainer-owned horses in a stable rather than stable size per se. Third, it is by no means clear that outside clients should end up with the best horses: the greater knowledge and expertise of trainers mean that they have a significant advantage in obtaining at least a partial ownership share in the horses most likely to succeed. ${ }^{14}$

Our results contrast with those obtained for the real estate industry by Levitt and Syverson (2005) and Rutherford et al. (2005). In those studies, real estate agents perform better when selling their own houses than when selling houses owned by clients. One difference between the two markets is that sales of agent-owned houses are only a tiny proportion of total sales, so the principal conflict of interest arises less often than in racehorse training. More importantly, real estate sales are typically one-shot deals offering little scope for repeat business with the same client, so there is relatively little to lose from exerting less-than-full effort on most occasions. This suggests that the situation faced by real estate agents is analogous to that of trainers with small stables and/or few outside clients.

It is interesting to speculate about the generality of our results and their potential applicability to other asset management settings. One reason why horse trainers are likely to be particularly sensitive to client interests is the unregulated nature of the labor market in which they operate: horses can, and do, transfer from one stable to another literally overnight. Most labor markets do not work as efficiently as this, making future income far less dependent on current performance. And although some other asset managers are potentially subject to similar discipline - it is usually simple enough to sack one's accountant or lawyer — performance is not always so easy to observe as at the racetrack. Nevertheless, our results provide some idea of what is possible in the right circumstances. Clearly, even expert-service markets are potentially transparent enough to eliminate agency problems.

Our analysis leaves some unresolved questions. First, we cannot rule out the possibility of reverse causation in our Section 5 results - perhaps trainers who treat clients best attract a lot of client-owned horses. Of course, this would simply reflect the mechanism underlying

\footnotetext{
${ }^{14} \mathrm{~A}$ fourth piece of evidence on this issue potentially comes from the sub-sample of horses that change from client- to trainer-ownership (or vice versa) during the course of a season. Within this sample, the group that stay in the same stable - which by definition cannot be beyond the trainer's financial reach — perform worse under client ownership, consistent with trainers exploiting their superior information about horse ability. But this effect is weaker in large stables and in stables with a large proportion of outside clients, thereby supporting our earlier results in a situation where trainer capital constraints are explicitly ruled out. However, the sample size is small and parameter estimates are marginally significant at best, so these results need to be viewed with caution.
} 
the differential-effort story — that clients discipline trainers for under-performance, thereby motivating the latter not to cheat. But does a tendency to put more effort into their own horses really have adverse consequences for trainers? Investigation of this issue would require tracking of the hiring-firing decisions of owners with respect to trainers, a feasible, if somewhat daunting, task. Second, why do some client-owners persist in using trainers who face weak incentives? We suspect that owners trade off the greater agency problems that arise in such stables against the more personalised service that they are able to provide, and that for some owners the latter outweighs the former.

Finally, could the performance premium enjoyed by client-owned horses in stables with the right incentives be exploited by racetrack bettors? Although we have not investigated this issue, we are doubtful that any such strategy could be successful. First, given the intensive scrutiny of track form by bettors, the information contained in ownership and stable type seems likely to be fully incorporated in race odds. Second, even if this were not the case, our results suggest only that profits are available over the course of a full season, exploitation of which would require deep pockets.

\section{References}

Chen, C. and J. Ritter, 2000. The seven percent solution. Journal of Finance 55, 1105-1131.

Fama, E., 1980. Agency problems and the theory of the firm. Journal of Political Economy 88, $288-307$.

Fernie, S. and D. Metcalf, 1999. It's not what you pay it's the way that you pay it and that's what gets results. Labour 13, 385-411.

Gompers, P. and J. Lerner, 1999. Conflict of interest in the issuance of public securities: evidence from venture capital. Journal of Law and Economics 42, 1-28.

Grant, D., 2000. Two Over Three on Goodtime Sugar: The New Zealand TAB Turns 50. Wellington: Victoria University Press.

Hausch, D., V. Lo and W. Ziemba (eds.), 1994. Efficiency of Racetrack Betting Markets. San Diego: Academic Press.

Henley Centre, 2004. A report of research on the horse industry in Great Britain. Report for the UK Department for Environment, Food and Rural Affairs;

http://www.defra.gov.uk/rural/horses/topics/research.htm

Hsieh, C. and E. Moretti, 2003. Can free entry be inefficient? Fixed commissions and social waste in the real estate industry. Journal of Political Economy 111, 1076-1119.

Hurley, W. and L. McDonough, 1995. A note on the Hayek hypothesis and the favorite long shot bias in parimutuel betting. American Economic Review 85, 949-955. 
IER, 2004. Size and scope of New Zealand racing industry: economic impacts and community social benefit. Report for the New Zealand Racing Board; http://www.nzracingboard.co.nz/

Klein, B. and K. Leffler, 1981. The role of market forces in assuring contractual performance. Journal of Political Economy 89, 615-641.

Levitt, S. and C. Syverson, 2005. Market distortions when agents are better informed: the value of information in real estate. NBER Working Paper W11053;

http://www.nber.org/papers/w11053

Michaely, R. and K. Womack, 1999. Conflict of interest and the credibility of underwriter analyst recommendations. Review of Financial Studies 12, 653-686.

Rutherford, R., T. Springer and A. Yavas, 2005. Conflicts between principals and agents: evidence from residential brokerage. Journal of Financial Economics 76, 627-665.

Sauer, R., 1998. The economics of wagering markets. Journal of Economic Literature 36, 2021-2064.

Telser, L., 1980. A theory of self-enforcing agreements. Journal of Business 53, 27-44.

Tolich M, 2002. Against the odds: the TAB and the sunset of the horse-racing industry. Gambling in New Zealand, ed. B Curtis. Palmerston North: Dunmore Press.

White, H., 1980. A heteroskedasticity-consistent covariance matrix estimator and a direct test for heteroskedasticity. Econometrica 48, 431-460.

Williams, J., 1998. Agency and brokerage of real assets in competitive equilibrium. Review of Financial Studies 11, 239-280. 